\title{
Esophageal peroral endoscopic myotomy (POEM) for treatment of esophagogastric junction outflow obstruction: results from the first prospective trial
}

다(1)이우

\author{
Authors \\ Khashab ${ }^{1}$ \\ Institutions \\ 1 Division of Gastroenterology and Hepatology, Johns \\ Hopkins Medical Institution, Baltimore, Maryland, \\ United States \\ 2 Department of Internal Medicine, Boston Medical \\ Center, Boston, Massachusetts, United States \\ 3 American University of Beirut School of Medicine, \\ Beirut, Lebanon
}

Yervant Ichkhanian ${ }^{1}$, Omid Sanaei ${ }^{1}$, Andrew Canakis ${ }^{2}$, Kia Vosoughi ${ }^{1}$, Erik Almazan ${ }^{1}$, Bachir Ghandour ${ }^{3}$, Mouen A

submitted 25.3.2020

accepted after revision 11.5 .2020

Bibliography

DOI https://doi.org/10.1055/a-1198-4643 |

Endoscopy International Open 2020; 08: E1137-E1143

(c) Georg Thieme Verlag KG Stuttgart · New York

elSSN 2196-9736

Corresponding author

Mouen Khashab, MD, Associate Professor of Medicine, Director of Therapeutic Endoscopy, Johns Hopkins Hospital, Sheikh Zayed Bldg, Division of Gastroenterology and Hepatology, 1800 Orleans Street, Suite 7125G, Baltimore, MD 21287

Fax: +1-443-683-8335

mkhasha1@jhmi.edu,www.hopkins-gi.org

\section{ABSTRACT}

Background and study aims Esophagogastric junction outflow obstruction (EGJOO) is a rare esophageal dysmotility disease that is characterized by elevated integrated relaxation pressuse (IRP) with evidence of preserved peristalsis. The role of peroral endoscopic myotomy (POEM) in management of EGJOO is currently unknown.

Patients and methods This is a prospective trial conducted in a single US tertiary care center from June 2015 to June 2019. Symptomatic patients, diagnosed with EGJOO on both HRM and endoluminal functional lumen imaging probe (EndoFLIP), who were eligible for POEM were recruited. Primary outcome was clinical success, defined as Eckardt score $(E S) \leq 3$, at 6 months post-POEM. Other outcomes included dysphagia score, quality of life as measured by 36-item Short Form health survey scales (SF-36), postPOEM HRM, EndoFLIP, and pH measurements, and adverse events.

Results A total of 15 patients ( 51.8 yr. 9 F) with EGJOO underwent POEM. Pre-POEM mean IRP on HRM and Distensibility index (DI) on EndoFLIP were $24.3 \pm 2.2 \mathrm{mmHg}$ and $1.1 \pm 0.6 \mathrm{~mm}^{2} / \mathrm{mmHg}$, respectively. Clinical success was achieved in $93 \%$ at 6 months post-POEM. There was significant decrease in IRP $(-17.6 \mathrm{mmHg})$ post-POEM. There was significant improvement at 6 months in two of the SF-36 subscales. Ten patients underwent post-POEM $\mathrm{pH}$ testing, seven of whom had abnormal DeMeester score. Seven patients underwent EGD evaluation revealing esophagitis in five ( 2 Los Angeles grade $A$ and 3 grade $B$ ).

Conclusions POEM offers a high clinical success rate for patients with EGJOO confirmed by impedance planimetry.

\section{Introduction}

Esophageal motility disorders comprise a wide array of clinicopathologic diseases that often require detailed diagnostic and therapeutic interventions. Within this spectrum, esophagogastric junction outflow obstruction (EGJOO) has emerged as a heterogeneous entity that can negatively impact patients' quality of life and manifests with regurgitation, dysphagia, and/or chest pain [1]. EGJOO diagnosis is made when high-resolution manometry (HRM) demonstrates an integrated relaxation pressure (IRP) $>15 \mathrm{mmHg}$ with evidence of preserved peristalsis [2]. Despite the importance of establishing a manometric diagnosis, exclusion of anatomic and mechanical causes of obstruction is crucial. In this context, other modalities, including endoscopic ultrasound and CT imaging, may be utilized to investigate malignant or infiltrative disorders [3]. When a me- 
chanical obstruction is ruled out, functional EGJOO should be entertained [4]

Based on the Chicago Classification [5], esophagogastric junction is categorized into achalasia with its subtypes, and EGJOO, which has preserved or fragmented peristaltic function. However, treatment options are similar in that the disruption of the lower esophageal sphincter may provide benefits in both disorders. While Peroral Endoscopic Myotomy (POEM) is established as a safe and effective treatment for patients with achalasia, its role in the management of EGJOO is not well known. In the only systematic review of 8 studies ( $n=184$ patients) examining medical, endoscopic, and surgical management of EGJOO, no POEM cases were included. Of note, in this study, botulinum toxin injection and expectant management were the two most frequent approaches, with success rates being $58 \%$ and $54 \%$, respectively [6]

There have been a few retrospective studies examining the role of POEM in non-achalasia esophageal motility disorders [7-12]. Collectively they have included a total of 3 patients with EGJOO who underwent POEM with promising technical and clinical efficacy; however, these retrospective studies also included other non-achalasia dysmotility disorders in their cohort and are limited by heterogeneous diagnostic and clinical efficacy assessment.

POEM has theoretically the potential to serve as a minimally invasive method in managing EGJOO patients with persistent symptoms. This prospective study aimed to evaluate the outcomes, efficacy, and safety of POEM in the management of EGJOO.

\section{Patients and methods}

This was a prospective trial conducted at a single US tertiary care center from June 2015 to June 2019. The protocol of the study was approved by the institutional review board (IRB), and informed consent was obtained from all participants. The study was registered on Clinicaltrials.gov, NCT01942018. Patients diagnosed with EGJOO who were eligible for POEM were recruited. Prior to referral for POEM, patients who were suspected to have extrinsic cause for esophageal outflow obstruction underwent further diagnostic testing modalities, endoscopic ultrasonography or computed tomography (CT) scan. The study coordinator and the endoscopist performing the procedure went over study-related items and explained the requirements and study obligations to all patients. All authors had access to the study data and approved the final manuscript. A separate protocol for post-trial retrospective chart review was approved by institutional review board to obtain long-term data on the participants.

Consecutive adult patients (18-80 years of age) with symptomatic dysphagia (dysphagia score $\geq 2$ and Eckardt score $\geq 3$ ) who had been diagnosed with EGJOO were included. The diagnosis of EGJOO was confirmed with both HRM [5] and Impedance planimetry [12]. All participants had the ability to provide informed consent. Exclusion criteria were pregnant or breastfeeding women (all female patients in childbearing age underwent urine pregnancy testing prior to POEM), coagulopa- thy (prothrombin time $<50 \%$ of normal control, partial thromboplastin time $>50$ seconds, international normalized ratio $>1.5$ or platelet count $<75,000 / \mu \mathrm{L}$ ), patients with cardiopulmonary instability or inability to tolerate sedation. Patients with acute esophagitis, hiatal hernia larger than $2 \mathrm{~cm}$, eosinophilic esophagitis, esophageal stricture or malignancy were also excluded.

\section{Clinical assessment before and after POEM}

On the day of the procedure, the clinical coordinator approached patients for obtaining the consent as well as the baseline/ pre-POEM Eckardt score, [13] dysphagia score, and Quality of life as measured by the validated Short Form-36 questionnaire. To determine the safety of the procedure, all intra- and postprocedure adverse events were recorded. Post-procedure follow-up included a phone call at 7 days and 28 days post-POEM to investigate any post-procedural adverse events. All procedural and post-procedural adverse events were reported and classified according to the ASGE Lexicon severity scoring system [14]. At day 28 post-POEM, patients were also asked about their diet tolerability. At 2-month and 6-month post-procedure, patients were contacted for obtaining their Eckardt score, dysphagia score, and 36-item Short Form health survey scales scores. Additionally, esophageal pH monitoring (by PH impedance or by wireless $\mathrm{pH}$-sensing capsule) and post-POEM HRM were performed at 2-months post-procedure. Routine clinical follow-up as per the standard of care was completed.

\section{POEM procedure}

All procedures were performed at Johns Hopkins Hospital, Baltimore, MD, by the principal investigator. Prior to the procedure, patients were nil per os (NPO) for $\geq 8 \mathrm{~h}$. On the day of the procedure, IV antibiotics were given and maintained during the hospital stay. POEM was then performed as described by Inoue et al [15]. An initial mucosal incision was performed in the 2- to 3-o'clock position on the right lateral esophageal wall with the aim of a straight tunnel ending at the lesser curvature at the cardia. Endoscopic submucosal dissection (ESD) knife (KD-640 L Triangle Tip (TT) Knife; Olympus) was used to access the submucosa, creating the submucosal tunnel and dissecting the circular muscle fibers over a minimum length of $4 \mathrm{~cm}$ in the esophagus, and $2 \mathrm{~cm}$ onto the cardia. Electro generator (Erbe Vio 300D; Erbe Elektromedizin, Tübingen, Germany) was used on EndoCut Q mode (effect 2) to create the mucosal incision, and spray coagulation mode (effect 2, 50 watts) to tunnel and dissect the muscle fibers. Closure of the mucosal entry site was performed using standard endoscopic clips. All the patients were admitted to the hospital wards for an overnight observation and post discharge standard of practice was followed by all. All patients underwent evaluation with endoluminal functional lumen imaging probe (EndoFLIPTM; Medtronic, Dublin, Ireland) before and after myotomy.

\section{Outcome}

The primary outcome was the rate of clinical success, defined as an Eckardt score (ES) $\leq 3$, at 6 months post-procedure. Patient clinical improvement was assessed by the ES (measuring the se- 
verity of dysphagia, chest pain, regurgitation, and chest pain), dysphagia score (measuring the diet tolerability), and 36-item Short Form health survey questionnaire (measuring the quality of life). Objective measures included post-procedure Impedance planimetry and HRM measurements. Impedance planimetry evaluation was performed at the end of the POEM session, and HRM was performed 2 months post-POEM. Secondary outcome included the rate of adverse events (AEs), length of hospital stay, total procedure time, development of postPOEM GERD as measured by objective $\mathrm{pH}$ monitoring tools (either 24-hour $\mathrm{PH}$ impedance) or the wireless $\mathrm{pH}$-sensing capsule) and Upper endoscopy findings including the prevalence of post-POEM esophagitis.

\section{Statistical analysis}

The desired sample size was calculated based on the Wilcoxon signed ranked test (matched pairs) and using $G^{*}$ Power 3.1 software. Two-sided 5\% significance level and 95\% power were used for sample size calculation. Based on our observation, we assumed a clinical success of $90 \%$ at 6 months. Considering all aforementioned assumptions, a sample size of 15 patients was needed for this study.

Baseline demographics, pre-, intra- and post-intervention data were prospectively collected on data collection forms, which were transferred and maintained in an electronic database system. Results were reported as mean \pm standard deviation (SD) for quantitative variables and percentages for categorical variables. We used Student's t-test for continuous variables and the chi-square test (or Fisher's exact test if required) for categorical variables. Statistical significance was based on two-sided design-based tests evaluated at $\alpha=0.05$. All statistical analyses were performed using SPSS (SPSS Inc, Chicago, Illinois, United States).

\section{Results}

During the duration of the study, June 2015 and June 2019, a total of 28 patients were suspected to have EGJOO on HRM evaluation. Subsequently, diagnosis of EGJOO was confirmed on EndoFLIP evaluation in 15/28 (54\%) patients (mean age $51.8 \pm 10.4$ yr., 9 [60\%] female) and were enrolled in the trial to undergo POEM for the management of EGJOO. One patient underwent further evaluation with endoscopic ultrasonography revealing thickened muscularis propria at the lower esophageal sphincter (LES) with no concerning lesions ( $>$ Table 1 ). Mean body mass index was $24.8 \pm 1.1 \mathrm{~kg} / \mathrm{m}^{2}$. Patients had a mean symptom duration of $60.1 \pm 10.8$ months. Five (33\%) patients had prior pneumatic balloon dilation (median balloon volume: $20 \mathrm{ml}$ [IQR: 15-30]) at a median time of 14 (IQR: 92.5) months pre-POEM, and one patient had both Balloon and Botulinum toxin injection at 4-month pre-POEM. The preprocedure median total Eckardt score (ES) was 6 [IQR: 5-7]. All patients underwent pre-procedure HRM evaluation in which the diagnosis of EGJOO, as opposed to other esophageal dysmotility disorders, was confirmed. HRM was performed at a median time of 134 (IQR: 14-425) days prior to the procedure.
Mean basal resting pressure (BRP) and (IRP) were $56 \pm 6.6$ and $24.3 \pm 2.2 \mathrm{mmHg}$, respectively.

\section{Procedure details}

The gastroesophageal junction (GEJ) was at mean distance of $39.9 \pm 4.1 \mathrm{~cm}$ from the incisors. The length of mucosal incision, submucosal tunnel, and myotomy had mean values of $2.2 \pm 0.9 \mathrm{~cm}, 12.7 \pm 2.1 \mathrm{~cm}$, and $10.1 \pm 2.3 \mathrm{~cm}$, respectively. The mean durations for completing the submucosal tunnel and the myotomy were 15 and 10.2 minutes, respectively, and the mean total procedure time was $51.8 \pm 16.8$ minutes. Triangular tip knife was used for submucosal tunneling and myotomy in all 15 cases. All mucosal incisions were closed using clips. No intraprocedural AEs were encountered; however, six cases had mild intra-procedural bleeding and were managed by coagulation forceps. Technical success was achieved in all 15 patients. Thirteen were discharged the next day, and two patients had a length of hospital stay of 3 days for comorbidities unrelated to the procedure.

Prior to discharge, all patients underwent esophagram, which confirmed the absence of leakage in all cases.

\section{Post-procedure follow-up}

All 15 patients completed the study follow-ups until 6 months post-procedure. At 1 week and 28 weeks post-procedure, two patients reported mild-to-moderate intensity substernal chest pain, which resolved with conservative management. The median time to resume normal diet was 2 weeks (IQR: 1-4).

At 2 months post-procedure, the clinical success was achieved in $100 \%$ of the patients, with a median total ES of 0 (IQR 0-1) and a median dysphagia score of 1 (IQR: $1-3)$. There was a significant improvement in median total ES after POEM (6 vs $0, P=0.02)$. At 6 months post-procedure, the clinical success was achieved in 14 (93.3\%) patients. The one patient with clinical failure had an ES of 7. The median total ES score at 6 months was 2 (IQR: 0-3) and median DS was 0 (IQR: 0-2). Repeated measures analysis of variance showed a significant improvement in the mean total ES $(p=0.02)$ and dysphagia score $(P=$ 0.045 ) across the follow-up intervals ( $\mathbf{F i g} \mathbf{1} \mathbf{1}$ ).

Quality of life questionnaires were completed by the 15 participants at baseline, 2 months and 6 months post-procedure follow-up. There was an improvement in all nine quality of life subscales that are measured by SF-36 when comparing baseline to post-POEM values ( $\$$ Table 3 ). Significant changes were in "role limitations due to physical health" subscale with a change in mean value from $30 \%$ at baseline to $80 \%$ at 6 months postPOEM and in "health change" with a change in mean value from $30 \%$ at baseline to $81 \%$ at 6 months post-POEM, $(P<0.05)$.

A total of 9 patients underwent HRM evaluation at a median time of 2 months (IQR: 1.3-2.8) post-procedure. Measured post-POEM mean BRP and IRP were $11.3 \pm 6.6 \mathrm{mmHg}$ and 11.3 $\pm 3.1 \mathrm{mmHg}$, respectively. There was a significant decrease in both BRP and IRP with a mean delta value of $-41.4 \mathrm{mmHg}(P=$ $0.03)$ and $-17.6 \mathrm{mmHg}(p=0.02)$, respectively.

All patients underwent pre- and post- POEM EndoFLIP evaluation with a pre-POEM mean Distensibility Index (DI) of $1.1 \pm$ $0.6 \mathrm{~mm}^{2} / \mathrm{mmHg}$ and $2 \pm 1.8 \mathrm{~mm}^{2} / \mathrm{mmHg}$ at 30 and $40-\mathrm{mL}$ bag 
- Table 1 Patient demographics and outcomes.

\begin{tabular}{|c|c|c|c|c|c|c|c|c|c|c|c|c|c|}
\hline $\begin{array}{l}\text { Pa- } \\
\text { tient }\end{array}$ & Sex & $\begin{array}{l}\text { BMI } \\
\mathrm{kg} / \mathrm{m} 2\end{array}$ & $\begin{array}{l}\text { Duration } \\
\text { of symp- } \\
\text { toms } \\
\text { months }\end{array}$ & $\begin{array}{l}\text { Pre- } \\
\text { POEM } \\
\text { BRP } \\
\mathrm{mmHg}\end{array}$ & $\begin{array}{l}\text { Pre- } \\
\text { POEM } \\
\text { IRP } \\
\text { mmHg }\end{array}$ & $\begin{array}{l}\text { Pre- } \\
\text { ES }\end{array}$ & $\begin{array}{l}\text { Pre- } \\
\text { DS }\end{array}$ & $\begin{array}{l}\text { Post- } \\
\text { POEM } \\
\text { ES score } \\
\text { at } 2 / 6 / \\
12 / 24 \\
\text { months }\end{array}$ & $\begin{array}{l}\text { Post- } \\
\text { POEM } \\
\text { BRP } \\
\mathrm{mmHg}\end{array}$ & $\begin{array}{l}\text { Post- } \\
\text { POEM } \\
\text { IRP } \\
\text { mmHg }\end{array}$ & $\begin{array}{l}\text { Post- } \\
\text { POEM De- } \\
\text { Meester } \\
\text { score }\end{array}$ & $\begin{array}{l}\text { Total \% } \\
\text { time } \\
\text { spent in } \\
\text { reflux }\end{array}$ & $\begin{array}{l}\text { Post-POEM } \\
\text { EGD find- } \\
\text { ing }\end{array}$ \\
\hline $1^{1}$ & M & 25.8 & 1 & 47.9 & 26.6 & 6 & 2 & $1 / 2 / 2 /-$ & 21.6 & 10.1 & $4.4^{2}$ & 0.9 & $\begin{array}{l}\text { Esophagitis } \\
\text { grade B }\end{array}$ \\
\hline 2 & M & 25.5 & 24 & 37.7 & 23.7 & 5 & 4 & $2 / 1 / 1 / 3$ & 21.8 & 7.9 & $60.9^{3}$ & 13.9 & $\begin{array}{l}\text { Esophagitis } \\
\text { grade A }\end{array}$ \\
\hline 3 & $\mathrm{~F}$ & 23.1 & 120 & 53.9 & 15.8 & 5 & 4 & $0 / 1 / 1 / 1$ & & & $105.8^{3}$ & 32.9 & Normal \\
\hline 4 & M & 28.1 & 12 & 121.9 & 50.8 & 4 & 1 & $0 / 2 / 1 / 2$ & & & & & \\
\hline 5 & $\mathrm{~F}$ & 34.6 & 120 & 56.4 & 18.4 & 6 & 2 & $0 / 0 / 1 / 1$ & 18.9 & 10.1 & $38.1^{3}$ & 9.5 & Normal \\
\hline 6 & $\mathrm{~F}$ & 30.3 & 72 & 19.7 & 18.2 & 5 & 0 & $0 / 3 / 1 / 2$ & 20.8 & 9 & $49^{3}$ & 14.8 & \\
\hline 7 & $\mathrm{~F}$ & 18.8 & 66 & 41.8 & 22 & 12 & 1 & $1 / 2 / 2 / 4$ & & & & & \\
\hline 8 & M & 28.8 & 60 & 25 & 18.5 & 6 & 0 & $5 / 7 / 3 / 4$ & 18.2 & 11.5 & $101.8^{3}$ & 29.4 & $\begin{array}{l}\text { Esophagitis } \\
\text { grade B }\end{array}$ \\
\hline 9 & $\mathrm{~F}$ & 23.3 & 12 & 79.6 & 23.3 & 7 & 1 & $2 / 2 / 2 / 3$ & 23.1 & 13.7 & $6.5^{3}$ & 1.6 & \\
\hline 10 & $\mathrm{~F}$ & 20.6 & 12 & 58.3 & 26.2 & 7 & 1 & $2 / 2 / 8 / 7$ & 38.3 & 18 & $14.3^{3}$ & 3.2 & $\begin{array}{l}\text { Esophagitis } \\
\text { grade B }\end{array}$ \\
\hline 11 & M & 25.3 & 120 & 62.7 & 16 & 1 & 1 & 0/0/0/- & & & & & \\
\hline $12^{4}$ & $\mathrm{~F}$ & 25 & 48 & 29.7 & 26.9 & 1 & 2 & $1 / 2 / 3 / 3$ & 24.7 & 9.1 & $40.2^{3}$ & 0.13 & $\begin{array}{l}\text { Esophagitis } \\
\text { grade A }\end{array}$ \\
\hline 13 & $\mathrm{~F}$ & 22.4 & 84 & 62.6 & 21.9 & 8 & 1 & $1 / 1 / 3 / 3$ & 32.2 & 12 & $38^{3}$ & 14.7 & \\
\hline 14 & $\mathrm{~F}$ & 20.9 & 96 & 74.7 & 23.6 & 5 & 1 & $0 / 3 / 3 /-$ & & & & & \\
\hline 15 & M & 19.5 & 55 & 68.1 & 33 & 8 & 2 & $0 / 1 / 5 /-$ & & & & & \\
\hline \multicolumn{14}{|c|}{$\begin{array}{l}\text { BMI, body mass index; POEM, peroral endoscopic myc } \\
\text { EGD, esophagogastroduodenoscopy } \\
{ }^{1} \text { This patient underwent endoscopic ultrasonography } \\
{ }^{2} \mathrm{pH} \text { testing done using } 48 \text {-hour } \mathrm{PH} \text {-sensing capsule } \\
{ }^{3} \mathrm{pH} \text { testing done using } 24 \text {-hour } \mathrm{pH} \text { impedance test } \\
{ }^{4} \text { Patient underwent Transoral Incisionless Fundoplicat }\end{array}$} \\
\hline
\end{tabular}

volume, respectively, and post-POEM mean DI of $4.5 \pm 2.4 \mathrm{~mm}^{2} /$ $\mathrm{mmHg}$ and $5.3 \pm 2.6 \mathrm{~mm}^{2} / \mathrm{mmHg}$, respectively. In general, preand post-myotomy impedance planimetry revealed a significant increase in the mean cross-sectional area, distensibility index, and compliance at $30-\mathrm{mL}$ and $40-\mathrm{mL}$ bag volumes $(P<$ 0.05) ( Table 2).

Post-procedure $\mathrm{pH}$ testing was performed in 10 patients at a median time of 4 months (IQR: 3-8) post-procedure. Mean DeMeester score was $43.6 \pm 29.3$, and $7(70 \%)$ patients had a score $>14.72$. The mean total $\%$ time spent in reflux was $12 \%$, with $6(60 \%)$ patients having abnormal values (normal reference of the $\mathrm{pH}$-sensing capsule being $\leq 5.3 \%$ and catheterbased $\leq 4.1 \%$ ). A total of seven patients underwent upper endoscopic evaluation at a mean follow-up time of $5.1 \pm 4.8$ months post-procedure. Esophagitis noted in 5 (71.4\%) patients (2 Los Angeles grade A and 3 grade B).

\section{Post-trial follow-up}

All patients completed their 1-year follow-up, and clinical success was achieved in 13 of 15 patients (87\%). Median Eckardt and dysphagia scores were $2(1-3)$ and $0(0)$, respectively. At 1-year follow-up, 13 of 15 patients were on full-dose PPI therapy. One patient, however, continued to have PPI-resistant gastroesophageal reflux and underwent Transoral Incisionless Fundoplication (TIF) procedure 8 months post-POEM.

\section{Discussion}

When evaluating esophageal dysmotility diseases by HRM, determining the presence or absence of EGJOO, as reflected by the IRP, is crucial for determining if LES targeted therapy, such as POEM, would be beneficial or not. Since its introduction [15], POEM has established itself as a minimally invasive LES-targeted therapy for management of achalasia; however, its role in non- 


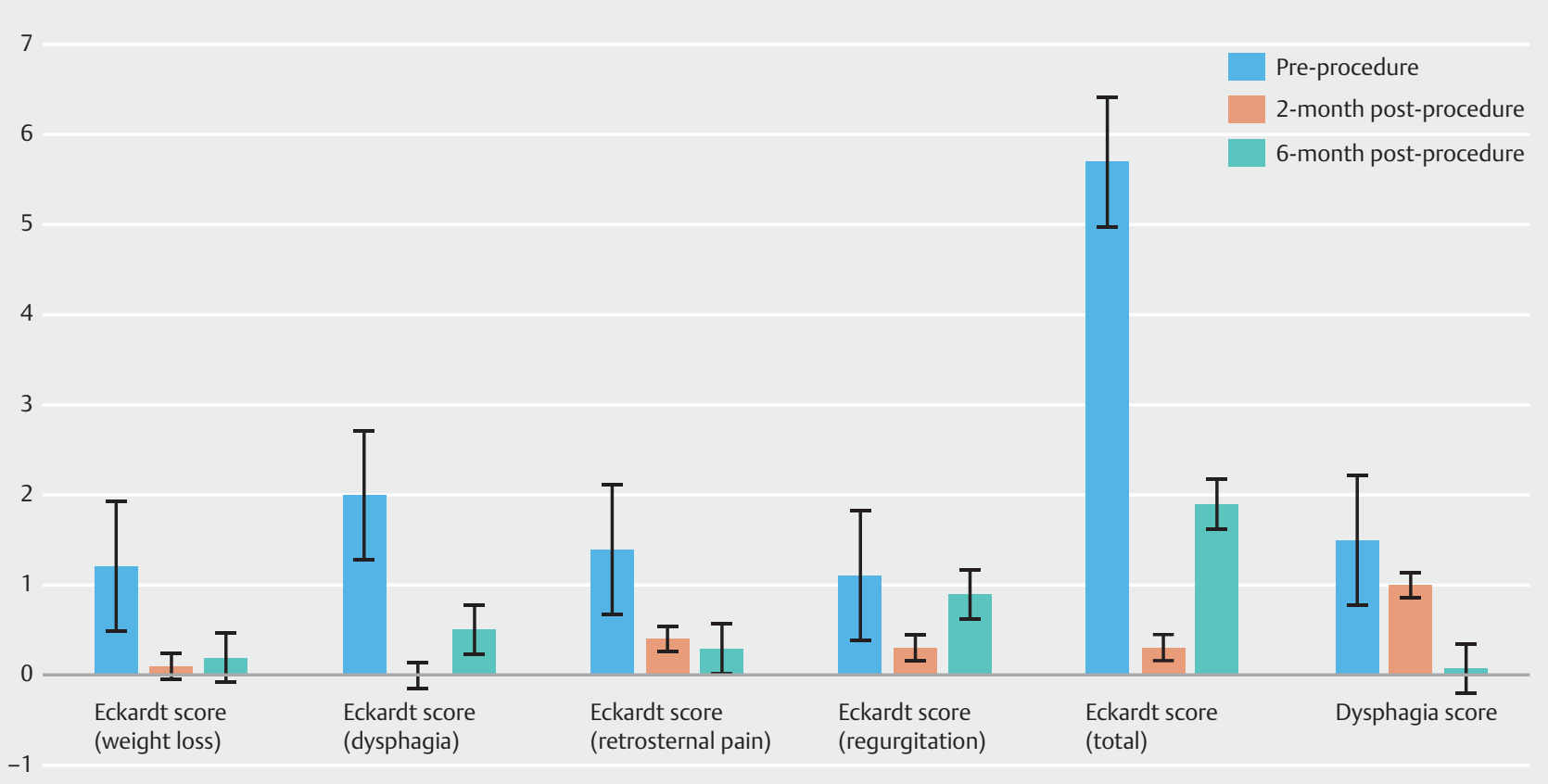

Fig. 1 Eckardt score (ES) and Dysphagia Score pre-procedure, 2 months, and 6 months post-procedure.

achalasia esophageal dysmotility disorders, such as EGJOO, remains poorly defined.

A recent case report described the feasibility of laparoscopic Heller myotomy for management of EGJOO [16]. Few studies have assessed the role of POEM in EGJOO and reported shortterm clinical efficacy ranging from $90 \%$ to $100 \%$ [7-11]. However, data remain limited to retrospective studies. In this study, we report the results of the first prospectively followed cohort of symptomatic patients diagnosed with EGJOO on both HRM and Impedance planimetry who underwent POEM with a rate of technical success (100\%), and a clinical success at 6 months of $93 \%$.

In general, a range of etiologies can be responsible for EG$\mathrm{JOO}$, and management outcomes depend on choosing the correct treatment strategy, which in turn depends on accurate diagnosis and differentiation of functional from mechanical EG-
JOO. Similar to achalasia, EGJOO shares a common primary abnormality in terms of failure of LES relaxation [17]. Asymptomatic or minimally symptomatic patients often require no treatment due to spontaneous symptom resolution in some patients [18]. However, for patients with persistent symptoms, endoscopic treatment options may include pneumatic dilation, botulinum toxin injection, and POEM [19]. HRM evaluation and objective $\mathrm{pH}$ testing post POEM are often utilized to differentiate pseudoachalasia, caused by GERD, characterized by abnormal $\mathrm{pH}$ testing, as opposed to true clinical failure, indicated by abnormally elevated IRP on HRM.

Adopting a cut off IRP value of $>15 \mathrm{mmHg}$ on HRM for diagnosis of EG]OO $[2,20]$ often results in overdiagnosis of clinically non-relevant EGJOO, which does not necessitate treatment. This could be overcome by setting a cut-off IRP value $\geq 20$ $\mathrm{mmHg}$ on HRM. This has been shown to segregate clinically rel-

- Table 2 Impedance planimetry evaluation results pre and post myotomy.

\begin{tabular}{|c|c|c|c|c|c|c|c|c|}
\hline & \multicolumn{4}{|c|}{$30-\mathrm{mL}$ bag volume } & \multicolumn{4}{|c|}{ 40-mL bag volume } \\
\hline & $\begin{array}{l}\text { Pre-proce- } \\
\text { dure }\end{array}$ & $\begin{array}{l}\text { Post-proce- } \\
\text { dure }\end{array}$ & $P$ value & Delta & $\begin{array}{l}\text { Pre-proce- } \\
\text { dure }\end{array}$ & $\begin{array}{l}\text { Post-proce- } \\
\text { dure }\end{array}$ & $P$ value & Delta \\
\hline Diameter (mm) & $6.3 \pm 1.7$ & $11.2 \pm 1.9$ & 0.06 & $5.8 \pm 3.6$ & $8.6 \pm 2.8$ & $14.2 \pm 2$ & 0.05 & $6.7 \pm 4.3$ \\
\hline $\operatorname{CSA}\left(\mathrm{mm}^{2}\right)$ & $33.5 \pm 20.3$ & $101.8 \pm 33.9$ & 0.04 & $73.8 \pm 43$ & $67 \pm 40.1$ & $149 \pm 39.5$ & 0.035 & $90.9 \pm 54.7$ \\
\hline Pressure $(\mathrm{mmHg})$ & $34 \pm 12.5$ & $24.9 \pm 6.7$ & 0.05 & $-4.3 \pm 20$ & $41.6 \pm 13.4$ & $31.3 \pm 8.8$ & 0.06 & $-4.8 \pm 22.1$ \\
\hline $\begin{array}{l}\text { Distensibility Index } \\
\left(\mathrm{mm}^{2} / \mathrm{mmHg}\right)\end{array}$ & $1.1 \pm 0.6$ & $4.5 \pm 2.4$ & 0.03 & $3.6 \pm 2.6$ & $2 \pm 1.8$ & $5.3 \pm 2.6$ & 0.045 & $3.5 \pm 2.6$ \\
\hline $\begin{array}{l}\text { Compliance } \\
\left(\mathrm{mm}^{3} / \mathrm{mmHg}\right)\end{array}$ & $35.4 \pm 6.2$ & $130.6 \pm 44.7$ & 0.01 & $16.7 \pm 44.9$ & $55.7 \pm 16$ & $118.8 \pm 14.5$ & 0.03 & $21 \pm 43$ \\
\hline
\end{tabular}


- Table 3 Short Form-36 questionnaire scores pre-procedure and 6 months post-procedure.

\begin{tabular}{|l|l|l|l|}
\hline Short Form-36 Subscales & $\begin{array}{l}\text { Pre-procedure } \\
\text { Mean } \pm \text { SD }\end{array}$ & $\begin{array}{l}\text { 6-months post-procedure } \\
\text { Mean } \pm \text { SD }\end{array}$ & P value \\
\hline Physical functioning & $69 \pm 291$ & $92.7 \pm 27$ & 0.01 \\
\hline Role limitations due to physical health & $31 \pm 31$ & $80.7 \pm 42$ & 0.03 \\
\hline Role limitations due to emotional problems & $60 \pm 24$ & $89 \pm 26$ & 0.23 \\
\hline Energy/fatigue & $50 \pm 26$ & $58.1 \pm 15$ & 0.08 \\
\hline Emotional well-being & $69 \pm 21$ & $71.4 \pm 12$ & 0.4 \\
\hline Social functioning & $52 \pm 15$ & $76.9 \pm 36$ & 0.05 \\
\hline Pain & $53 \pm 34$ & $76.3 \pm 35$ & 0.21 \\
\hline General health & $48 \pm 29$ & $80 \pm 17$ \\
\hline Health change & $30 \pm 21$ & 0.09 \\
\hline 'Higher scores indicates better health-related quality of life & & \\
\hline
\end{tabular}

evant from non-relevant EGJOO [21]. Use of other diagnostic tools such as functional luminal imaging probe (FLIP) technology can also aid in the selection of clinically-relevant EGJOO [12]. In our cohort, all patients underwent pre-POEM EndoFLIP evaluation to confirm the diagnosis of EGJOO, with a mean prePOEM DI of $1.1 \pm 0.6 \mathrm{~mm} 2 / \mathrm{mmHg}$ and $2 \pm 1.8 \mathrm{~mm} 2 / \mathrm{mmHg}$ at $30-\mathrm{mL}$ and $40-\mathrm{mL}$ balloon volumes, respectively. The high clinical response of EGJOO to POEM in the current study is likely due to confirmation of "real" EGJOO by impedance planimetry. It is plausible that POEM will be associated with a much lower response rate if EGJOO is not confirmed by alternative means (e. g. flip or timed barium esophagram).

Although the sample size requirements were met statistically, the small sample size and short follow-up duration are major limitations of this study. EGJOO is uncommon as opposed to achalasia (289 achalasia patients underwent POEM during the duration of this trial at our center). Future trials with larger sample size are still needed to confirm the study results. In addition, not all patients completed post-POEM HRM and pH metry testing. Nonetheless, this is the first prospective study to assess the role of POEM for EGJOO and has direct impact on management of these patients.

\section{Conclusion}

In conclusion, we report high clinical efficacy and safety of POEM in the management of EGJOO. EGJOO diagnosis needs to be confirmed (e.g. by impedance planimetry) before offering therapies directed at the lower esophageal sphincter.

\section{Competing interests}

Dr. Khashab is consultant for Boston Scientific, Medtronic and Olympus.
References

[1] Triadafilopoulos G, Clarke JO. Clinical and manometric characteristics of patients with oesophagogastric outflow obstruction: towards a new classification. BMJ Open Gastroenterol 2018; 5: e000210

[2] Kahrilas PJ, Bredenoord AJ, Fox M et al. The Chicago Classification of esophageal motility disorders, v3.0. Neurogastroenterol Motil 2015; 27: $160-174$

[3] Scherer JR, Kwiatek MA, Soper N] et al. Functional esophagogastric junction obstruction with intact peristalsis: a heterogeneous syndrome sometimes akin to achalasia. J Gastrointest Surg 2009; 13: 2219-2225

[4] Kahrilas PJ, Boeckxstaens G. The spectrum of achalasia: lessons from studies of pathophysiology and high-resolution manometry. Gastroenterology 2013; 145: 954-965

[5] The Chicago Classification of Esophageal Motility Disorders, v3.0. Neurogastroenterol Motil 2015; 27: 160-174

[6] Garbarino S, von Isenburg M, Fisher DA et al. Management of functional esophagogastric junction outflow obstruction: a systematic review. J Clin Gastroenterol 2020; 54: 35-42

[7] Filicori F, Dunst CM, Sharata A et al. Long-term outcomes following POEM for non-achalasia motility disorders of the esophagus. Surg Endosc 2019; 33: 1632-1639

[8] Okeke FC, Raja S, Lynch KL et al. What is the clinical significance of esophagogastric junction outflow obstruction? evaluation of 60 patients at a tertiary referral center. Neurogastroenterol Motil; 2017

[9] Teitelbaum EN, Dunst CM, Reavis KM et al. Clinical outcomes five years after POEM for treatment of primary esophageal motility disorders. Surg Endosc 2018; 32: 421-427

[10] Masadeh MM, Chandra S, Shen $\mathrm{H}$ et al. Per-oral endoscopic myotomy for achalasia, esophagogastric junction outflow obstruction and diffuse esophageal spasm; a Us tertiary care center experience. Gastrointest Endosc 2017: AB579-AB580

[11] Khashab MA, Familiari P, Draganov PV et al. Peroral endoscopic myotomy is effective and safe in non-achalasia esophageal motility disorders: an international multicenter study. Endosc Int Open 2018; 6: E1031-e1036

[12] Carlson DA, Kahrilas PJ, Lin Z et al. Evaluation of esophageal motility utilizing the functional lumen imaging probe (FLIP). Am J Gastroenterol 2016; 111: 1726-1735 
[13] Eckardt VF, Aignherr C, Bernhard G. Predictors of outcome in patients with achalasia treated by pneumatic dilation. Gastroenterology 1992; 103: 1732-1738

[14] Cotton PB, Eisen GM, Aabakken L et al. A lexicon for endoscopic adverse events: report of an ASGE workshop. Gastrointest Endosc 2010; 71: 446-454

[15] Inoue H, Minami H, Kobayashi Y et al. Peroral endoscopic myotomy (POEM) for esophageal achalasia. Endoscopy 2010; 42: 265-271

[16] Pereira PF, Rosa AR, Mesquita LA et al. Esophagogastric junction outflow obstruction successfully treated with laparoscopic Heller myotomy and Dor fundoplication: First case report in the literature. World J Gastrointest Surg 2019; 11: p. 112-116

[17] Samo S, Qayed E. Esophagogastric junction outflow obstruction: Where are we now in diagnosis and management? World J Gastroenterol 2019; 25: 411-417
[18] Schupack D, Katzka DA, Geno DM et al. The clinical significance of esophagogastric junction outflow obstruction and hypercontractile esophagus in high resolution esophageal manometry. Neurogastroenterol Motil 2017; 29: 1-9

[19] Clayton SB, Patel R, Richter JE. Functional and anatomic esophagogastic junction outflow obstruction: manometry, timed barium esophagram findings, and treatment outcomes. Clin Gastroenterol Hepatol 2016; 14: 907-911

[20] Roman S, Gyawali CP, Xiao Y et al. The Chicago classification of motility disorders: an update. Gastrointest Endosc Clin N Am 2014; 24: 545-561

[21] Song BG, Min YW, Lee $\mathrm{H}$ et al. Clinicomanometric factors associated with clinically relevant esophagogastric junction outflow obstruction from the Sandhill high-resolution manometry system. Neurogastroenterol Motil 2018: 30 